\title{
Thoughts on the Laffer Curve
}

\author{
ALAN S. BLINDER
}

... the ideas of economists and political philosophers, both when they are right and when they are wrong, are more powerful than is commonly understood. Indeed the world is ruled by little else.

-I. M. Keynes

The first part of the paper by Canto, Joines, and Laffer, which is the only part I will discuss, sets up a simple general equilibrium model with two factors (both taxed proportionately) and one output, and proceeds to grind out the solutions. The model, while not entirely unobjectionable, is certainly not outlandish in any important respect. The authors make no claims that the model tells us anything about the U.S. economy; nor do they draw any policy conclusions. They use the model to provide intellectual underpinnings for the celebrated "Laffer Curve" - the notion that the function relating tax receipts to tax rates rises to a peak and then falls. Since, as I will point out shortly, the analytical foundations of the Laffer curve were in fact established centuries ago, and require no economic analysis at all, I will devote my comments to the critical empirical issue: is it possible that taxes in the U.S. have passed the points at which tax receipts cease rising? Is the U.S. tax system over the Laffer hill?

Let me note at the outset why this is an important question. Certainly not because of the implications for the government deficit. Surely what a tax change does to the budget deficit must be one of the least important questions to ask. It is important to know which taxes, if any, have reached the downside of the Laffer hill because, in an optimal taxation framework, tax rates should be set to raise whatever revenues are required with minimum deadweight loss. ${ }^{1}$ Since a tax that is past this point causes deadweight loss and

Alan S. Blinder is Professor of Economics, Princeton University, and Research Associate, National Bureau of Economic Research, Cambridge, Mass.

'The statement assumes that lump sum taxes afe unavailable and ignores distributional objectives. 
FIGURE 1

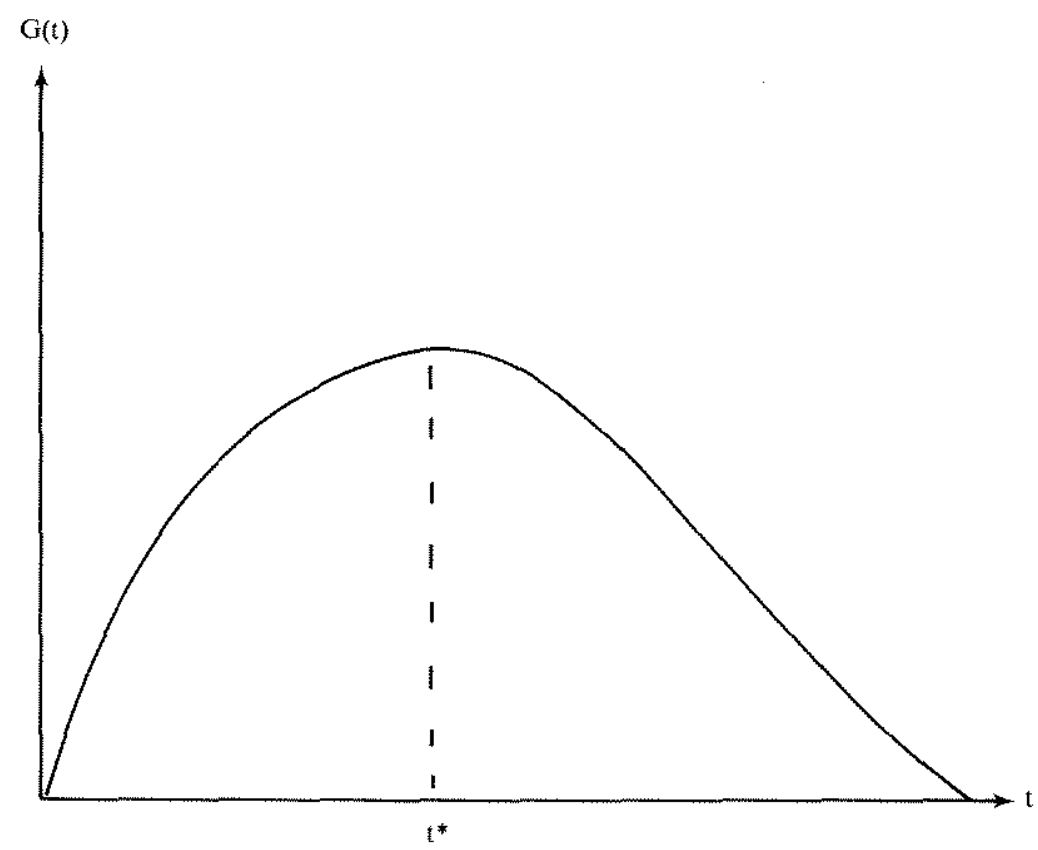

makes a negative contribution to revenue, it must be irrationally high, as Canto, Joines and Laffer correctly state. ${ }^{2}$

\section{ORIGINS OF THE LAFFER CURVE}

Figure 1 is a Laffer curve relating tax receipts, $G$, to the tax rate, t. For some types of taxes (example: income taxes), the tax rate has a natural upper bound at $100 \%$, so we may assume that $\mathrm{G}(1)=0$. For others (example: excise taxes) there is no such natural bound at $100 \%$, so we assume instead that $G$ asymptotically approaches zero as $t$ approaches infinity. The distinction is not terribly important so long as we keep in mind that taxes greater than $100 \%$ are indeed possible in many cases. ${ }^{3}$ The Laffer curve reaches its peak at tax rate $t^{*}$, which $I$ hereafter call the Laffer point.

"Such a lax might be rational if its avowed purpose was to "distort" behavior (e.g., an emissions tax to reduce polfution). A purely redistributive objective is also a potential rationale; but there must be better ways to redistribute income.

${ }^{3}$ Taxes on such items as cigarettes, liquor, and gasoline have exceeded $100 \%$ of the producer's price in many times and places. 
According to the media, the Laffer curve was born on a napkin in a Washington restaurant in 1974. This, however, I know to be wrong. The Laffer curve should perhaps be called the Dupuit Curve, because Dupuit - a man who was ahead of his times in many respects - wrote in 1844 that: ${ }^{*}$

If a tax is gradualy increased from zaro up to the point where it becomes prohibitive, its yield is at first nil, then increases by small stages until it reaches a maximum, after which it gradually declines until it becomes zero again.

But Dupuit was just an academic scribbler distilling his frenzy from a politician of a bygone age. In parliament in 1774, Edmund Burke used what was perhaps called the Burke Curve by the journalists of the day to argue against overtaxation of the American colonists:

Your scheme yields no revenue; it yields nothing but discontent, disorder, disobedience; and such is the state of America, that after wading up to your eyes in blood, you could only end just where you began; that is, to tax where no revenue is to be found...

But, alas, we cannot credit Burke with the idea either, for the concept goes back even further and is far more basic. One of the first things that freshmen learn in their first course in calculus is Rolle's Theorem. Rolle's Theorem is as follows. Let $G(t)$ be any continuous and differentiable function with $G(a)=0$ and $G(b)=$ 0 . Then there must be some point $t^{*}$ between $a$ and $b$ such that $G^{\prime}\left(t^{*}\right)=0$. Let $a=0, b$ be either 1 or infinity, depending on the type of tax under consideration, add the proviso that $G^{\prime}(0)>0$, and you have a Laffer curve. The existence of a Laffer curve, in other words, is not a result of economics at all, but rather a result of mathematics. We cannot doubt that there is a Laffer hill, i.e., there is a tax rate that maximizes tax receipts, so long as the assumptions of Rolle's Theorem are granted. Are they? I think we do not want to quibble with continuity or differentiability, and it must be true that a tax rate of zero yields no revenue. This leaves only the endpoint condition-either $\mathrm{G}(1)=0$ or $\mathrm{G}(\infty)=0$, depending on the type of tax in question. But $I$, for one, am willing to accept that a $100 \%$ income tax rate or an infinite sales tax rate will, to a first approximation, eliminate the taxed activity entirely. The Laffer curve almost certainly exists.

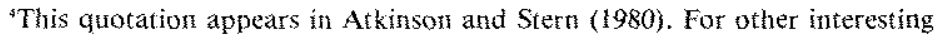
precursors, see Canto, Joines and Webb (1979). 


\section{ARE WE OVER THE LAFFER HILL?}

I now turn to the question at hand. Is it plausible that the tax rates we observe in the real world are greater than $t^{*}$, so that we are operating on the down side of the Laffer hill?

First a preliminary point. We all know that the applicability of the Laffer clurve hinges on elasticities being "large" in some sense. (1 will be thore precise in a moment.) Thus the possibitity of taxing beyond the Laffer point is much more real for taxes whose bases are narrowly defined - either in time, or in geographical space, or in commodity space - than it is for taxes that are broadly based. Let me illustrate. A sales tax on pastrami is much more likely to have a negative marginal revenue yield than a sales tax on all food, simply because of the much greater substitution possibilities on both the demand side and the supply side of the market for pastrami, as compared to the market for all food. Similarly, I rather doubt that an income tax on earnings between noon and 2 p.m. on Wednesdays would bring in much revenue. As a final example, I have heard it claimed that if New York City raised its sales tax, but the surrounding states and counties did not, revenues would actually decline. The possibility of being over the Laffer hill, I submit, is a very real one for very narrowly defined taxes. This, of course, merely strengthens the argument - which economists have been making for eons, it seems-for using broadly-based taxes rather than narrow ones.

The important question for current public policy debates, as 1 understand it, is: Can it be that some of our broadly-based taxeslike the personal and corporate income taxes - have passed the Laffer point? This seens to me highly implausible, and let me explain why.

Tax receipts are the product of the tax rate times the tax base. For ad valorem taxes, the latter is itself the product of a price (the net-of-tax price) and a quantity. ${ }^{5}$ Thus:

$$
\mathrm{G}=\mathrm{tpQ} \text {. }
$$

Since $t$ affects both $\mathrm{p}$ and $\mathrm{Q}$, the derivative $\frac{\mathrm{d} G}{\mathrm{dt}}$ has three terms. The first term:

$$
\mathrm{pQ}
$$

might be called (with some unfairness to the Treasury) the naive

Tassume markets clear so quantity demanded and quantity supplied are equal. 
Treasury term. It would be a good estimate of marginal tax yield if there were no behavioral responses. The second term:

$$
\text { tp } \frac{\mathrm{dQ}}{\mathrm{dt}}
$$

is the effect of the celebrated tax "wedge." Normally, we expect a contraction in the level of any activity whose tax is raised, so this term makes a negative marginal revenue contribution. The third term:

$$
\mathrm{tQ} \frac{\mathrm{dp}}{\mathrm{dt}}
$$

is the effect that arises from the fact that market prices generally change when tax rates change. Laffer et al. suggest that some economists have been led to underestimate the potency of the Laffer effect by ignoring general equilibrium reactions. Exactly the reverse seems to be true for many taxes. Consider, for example, a tax on a factor income where $\mathrm{p}$ is the price the firm pays and $p(1-t)$ is the price the factor supplier receives. Standard tax incidence theory suggests that normal market reactions would make $\mathrm{p}$ rise and $\mathrm{p}(\mathrm{l}-\mathrm{t})$ fall when $\mathrm{t}$ increases, suggesting that this third term is positive, not negative. Similarly, if there are possibilities for factor substitution, the demand curves for competing factors of production would be expected to shift out; if these factors are taxed, this will also bring in more revenue. ${ }^{6}$

The shape of the Laffer curve depends on the balancing of these three forces. It is clear that if $t^{*}$ is to occur at an empirically meaningful level, the "wedge" effect will have to be quite large. To illustrate the conditions that are necessary, let us work out a concrete example of a flat rate tax on labor income. Let $W$ be the wage the firm pays and $W(1-t)$ be the wage the worker receives. Let $S(W(l-t))$ be the supply function and $D(W)$ be the demand function, and assume $S(0)=0$ so that a Laffer curve exists. Tax receipts are:

$$
G(t)=t W S(W(l-t)),
$$

from which it follows by some simple algebra that marginal tax yield is:

$$
\frac{\mathrm{dG}}{\mathrm{dt}}=\mathrm{W} \cdot S(\cdot)\left[1-\frac{\mathrm{t}}{1-\mathrm{t}} \eta_{\mathrm{s}}+\frac{\mathrm{t}}{\mathrm{W}} \frac{\mathrm{dW}}{\mathrm{dt}}\left(1+\eta_{\mathrm{s}}\right)\right],
$$


where $\eta_{s}$ is the elasticity of supply:

$$
\eta_{\mathrm{s}}=\frac{\mathrm{W}(\mathrm{l}-\mathrm{t}) \mathrm{S}^{\prime}(\mathrm{W}(1-\mathrm{t}))}{\mathrm{S}}>0 \text {. }
$$

The positive Treasury effect, the negative wedge effect, and the positive price effect mentioned above can be seen clearly here. Working out the elasticity of $\mathrm{W}$ with respect to $t$, and substituting it into (3) gives:?

$$
\frac{\mathrm{dG}}{\mathrm{dt}}=\mathrm{WS}(\cdot)\left[1+\frac{\mathrm{t}}{1-\mathrm{t}} \frac{\eta_{\mathrm{s}}\left(1+\eta_{\mathrm{D}}\right)}{\eta_{\mathrm{s}}-\eta_{\mathrm{D}}}\right]
$$

where $\eta_{D}$ is the elasticity of demand:

$$
\eta_{\mathrm{D}}=\frac{\mathrm{WD}^{\prime}(\mathrm{W})}{\mathrm{D}}<0 \text {. }
$$

Notice that (4) cannot possibly be negative in the range where demand is inelastic. The Laffer point, $t^{*}$, is found by setting (4) equal to zero:

$$
t^{*}=\frac{\eta_{S}-\eta_{D}}{-\eta_{D}\left(1+\eta_{S}\right)} .
$$

Table 1 shows the values of $t^{*}$ for selected values of the two elasticities. It is clear that, untess the elasticities are quite high, we can be over the Laffer hill only when marginal tax rates are extremely high. For example, even if each elasticity is as high as 2 , receipts continue to rise until the tax rate reaches two-thirds. In other words, it is very unlikely (though not totally impossible) that the peak in the Laffer curve comes at a tax rate that anyone might seriously entertain.

By exactly the same procedure, it is possible to work out the formula for the peak of the Laffer hill for the case of an excise tax at rate $t$ on a commodity with producer price $p$ and consumer price $\mathrm{p}(1+\mathrm{t})$. The answer is:

$$
t^{*}=\frac{\eta_{S}-\eta_{D}}{-\eta_{S}\left(1+\eta_{D}\right)},
$$

and Table 2 provides numerical values for selected elasticities. It is clear once again that $t^{*}$ is a huge number unless the elasticities are incredibly high. For example, with elasticities of 2 for both supply

This is, of course, not a generat equilibrium analysis, since I consider only one market in isolation. I think most economists would be very surprised if a multimarket setting changed things very much. In any case, the next section takes up a general equilibrium example. 
and demand, tax revenues are maximized at a tax rate of $200 \%$. Elasticities as high as 5 are necessary to get $t^{*}$ as low as $50 \%$.

1 conclude, therefore, that the revenue-maximizing tax rate is very likely to be so high as to be considered ridiculous for any broad-based tax. Only very narrowly based taxes, where elasticities in the neighborhood of 5 start to become at least believable, are likely to encounter the down side of the Laffer hill. For the important taxes in our economy, the laffer curve holds no more interest than Rolle's Theorem.

\section{THE CANTO, JONES, AND LAFFER (CHL) MODEL}

Now the examples just considered were mine, not Laffer's. So let me turn next to the empirical relevance of the Laffer curve in the model proposed by the authors. The model has perfectly conventional demands for two factors (called labor and capital, though both are variable) derived from a Cobb-Douglas production function. The factor supply equations are somewhat unconventional, so let me explain them a bit and interpret the parameters.

Households hold fixed supplies of capital and labor, which they

TABLE 1

Values of $t^{*}$ from Equation ( 5 )

\begin{tabular}{|c|c|c|c|c|c|c|c|}
\hline \multirow{4}{*}{$\begin{array}{l}\text { Value } \\
\text { of }\end{array}$} & \multirow{4}{*}{$\begin{array}{r}\text { below } 1.0 \\
1.0\end{array}$} & \multicolumn{6}{|c|}{ Value of $\eta_{s}$} \\
\hline & & 0 & .25 & .50 & 1.0 & 2.0 & 5.0 \\
\hline & & 1.00 & $\leftrightarrow$ & \multicolumn{3}{|c|}{ more than 1.00} & $\rightarrow$ \\
\hline & & 1.00 & 1.00 & 1.00 & 1,00 & 1.00 & 1.00 \\
\hline \multirow[t]{2}{*}{$-\eta_{0}$} & 2,0 & 1.00 & .90 & .83 & .75 & .67 & .58 \\
\hline & 5.0 & 1.00 & .84 & .73 & .60 & .47 & .33 \\
\hline
\end{tabular}

TABLE 2

Values of t* from Equation (6)

Value of $\eta_{\mathrm{S}}$

\begin{tabular}{|c|c|c|c|c|c|c|c|}
\hline \multirow{2}{*}{$\begin{array}{c}\text { Value } \\
\text { of }\end{array}$} & \multirow[b]{2}{*}{ I or below } & 0 & .25 & .50 & 1.0 & 2.0 & 5.0 \\
\hline & & $\leftrightarrow$ & \multicolumn{4}{|c|}{ infinity } & $\rightarrow$ \\
\hline$-\eta_{\mathrm{D}}$ & 2.0 & $\infty$ & 9.0 & 5.0 & 3.0 & 2.0 & 1.4 \\
\hline & 5.0 & $\infty$ & 5.25 & 2.75 & 1.5 & .88 & .50 \\
\hline
\end{tabular}


can either supply to the market - at net-of-tax returns $\mathrm{R}^{*}$ and $\mathrm{W}^{*}$ respectively - or reserve for home production. Laffer et al. view the factor supply decision in a kind of "utility tree" framework. First, the household considers the choice of devoting its resources to the market versus home sectors; this choice depends on the average level of market returns relative to the average level of home returns (the latter is, I suppose, always unity). Second, the household decides on its relative factor supplies to the market by looking at relative market prices. This analysis suggests supply functions (assuming constant elasticity functional forms):

$$
\begin{array}{ll}
\mathrm{L}^{s}=\left[\left(\mathrm{R}^{*}\right)^{\alpha}\left(\mathrm{W}^{*}\right)^{1-\alpha}\right]^{\varepsilon}\left(\frac{\mathrm{W}^{*}}{\mathrm{R}^{*}}\right)^{\beta} \quad \varepsilon>0, \beta>0 \\
\mathrm{~K}^{*}=\left[\left(\mathrm{R}^{*}\right)^{\alpha}\left(\mathrm{W}^{*}\right)^{\mathrm{i}-\alpha}\right]^{\varepsilon}\left(\frac{\mathrm{R}^{*}}{\mathrm{~W}^{*}}\right)^{\lambda} \quad \lambda>0
\end{array}
$$

where $\left[\left(R^{*}\right)^{a}\left(W^{*}\right)^{i-a}\right]$ is the (geometric) weighted average of market returns, weighted by the production function weights. The use of the same " $E$ " parameter in (7) and (8) reflects the assumption of CJ that the ratio of $L$ to $K$ depends only on the ratio $W^{*} / R^{*}$. A tiny bit of manipulation puts (7) and (8) into the form of equations (7) and (8) in the CJL paper:

$$
\begin{aligned}
& \mathrm{K}^{s}=\left(\frac{\mathrm{R}^{*}}{\mathrm{~W}^{*}}\right)^{\lambda-\xi(1-*)}\left(\mathrm{R}^{*}\right)^{\xi} \\
& \mathrm{L}^{s}=\left(\frac{\mathrm{W}^{*}}{\mathrm{R}^{*}}\right)^{\beta-\varepsilon a}\left(\mathrm{~W}^{*}\right)^{\varepsilon}
\end{aligned}
$$

so that the parameters $a_{K}$ and $o_{L}$ that appear in the CJL paper are seen to have the following interpretations:

$$
\begin{aligned}
& \sigma_{\mathrm{K}}=\lambda-\varepsilon(l-\alpha) \\
& \sigma_{\mathrm{L}}=\beta-\varepsilon \alpha .
\end{aligned}
$$

The authors assume these parameters to be negative, which means they are assuming a fairly sizable value for $\varepsilon$-which is the one unconventional parameter in this model. The interpretation of $\varepsilon$ is the general price elasticity of supply of factors to the market sector (from the home sector). That is, if both $\mathrm{W}^{*}$ and $\mathrm{R}^{*}$ were to increase by $1 \%$, then the supplies of both capital and labor to the market would increase by $\varepsilon \%$. This is not a parameter for which much empirical evidence is available.

The authors take pains to make clear that income effects are ignored in their analysis because marginal tax receipts (positive or 
negative) are redistributed to the populace in a nondistorting way. In theory, this is correct. In practice, three caveats must be entered.

First, it seems inconsistent to assume that revenue can be raised only by distortionary taxes, but can be given away in a nondistortionary way. Surely, any real way to give back the revenue (through transfer payments or government gifts of goods and services) will be just as distortionary as taxes. And isn't reducing lump sum transfers the same as levying lump sum taxes?

Second, for the argument to hold, it is necessary that the recipients of the (lump sum?) transfers be the same as the payers of the additional taxes. If, for example, we consider cutting capital taxation and making up for the lost revenue by reducing transfers for the poor, there is no reason to think that income effects are of second order. In fact, I would be inclined to think that income effects would be of first order and substitution effects of second order.

Third, it should be understood that the thought experiments considered in the paper are balanced-budget alterations in the tax structure, so we cannot really speak of revenue effects and Laffer curves at all. The model assumes that lump sum transfers are available, and what appear to be "Laffer curves" in Figures 2 and 3 represent instead the behavior of aggregate lump sum transfers as tax rates are increased. If we really care about Laffer curves we cannot ignore income effects.

Nothing more need be said about the structure of the model. CJL correctly work out the solutions for prices and quantities and then compute the revenue-maximizing tax rates on capital and labor (their equations (27) and (28)). These can be simplified to:

$$
\begin{aligned}
& \mathrm{t}_{\mathrm{L}}^{*}=\frac{\lambda+(1-\alpha)}{(1-\alpha)(1+\varepsilon)(1+\lambda+\beta)} \\
& \mathrm{t}_{\mathrm{K}}^{*}=\frac{\beta+\alpha}{\alpha(1+\varepsilon)(1+\lambda+\beta)}
\end{aligned}
$$

Let me now pose the $\$ 64$ question. Is it possible that the tax rates implied by these formulas could be anywhere near current tax rates, which I take to be approximately $t_{L}=.3$ and $t_{K}=.4$ ?

There are four parameters in these formulas, The one we know fairly well is capital's share, $\alpha$, which I take to be $.25 . \beta$ is approximately the (compensated) wage elasticity of labor supply in the aggregate. There is much empirical evidence on labor supply. My reading of the evidence suggests that the lowest and highest values that can be seriously entertained are 0 and 0.6 respectively. 


\section{TABLE 3}

Values of $t_{\mathrm{L}}^{*}$ and $t_{\mathrm{K}}^{*}$ from Equations (9) and (10)

high elasticities

low elasticities

high elasticities

low elasticities

high elasticities

low elasticities

\begin{tabular}{ll}
\multicolumn{2}{c}{$\varepsilon=0$} \\
\hline $\mathrm{t}_{\mathrm{L}}^{*}=.77$ & $\mathrm{t}_{\mathrm{K}}^{*}=\mathrm{NE}$ \\
$\mathrm{t}_{\mathrm{L}}^{*}=.91$ & $\mathrm{t}_{\mathrm{K}}^{*}=\mathrm{NE}$
\end{tabular}

$\varepsilon=1$

$\begin{array}{ll}\mathrm{t}_{\mathrm{L}}^{*}=.38 & \mathrm{t}_{\mathrm{K}}^{*}=.85 \\ \mathrm{t}_{\mathrm{L}}^{*}=.45 & \mathrm{t}_{\mathrm{K}}^{*}=.64\end{array}$

$\varepsilon=2$

\begin{tabular}{ll}
\hline $\mathrm{t}_{\mathrm{L}}^{*}=.26$ & $\mathrm{t}_{\mathrm{K}}^{*}=.57$ \\
$\mathrm{t}_{\mathrm{L}}^{*}=.30$ & $\mathrm{t}_{\mathrm{K}}^{*}=.42$
\end{tabular}

$\mathrm{NE}=$ Nonexistent (i.e., no tax rate under $100 \%$ solves equation (10)).

$\lambda$ is a trickier parameter; it is the elasticity of capital supply to the market (versus to the home sector) with respect to the rate of return. It is hard to know what to make of this parameter in a static model. Will I really keep my capital home if the return in the market is low? Doing what? In a dynamic model, I guess households supply capital to the market by saving, and the steadystate interest elasticity of capital is the same as the interest elasticity of saving. I think the absolute limits on reasonable estimates of the interest elasticity of saving are probably $-.05<\lambda<+.40$, with zero a strong candidate. This leaves the unconventional parameter $\varepsilon$. Since I have no idea of how to "guesstimate" $\varepsilon$, I will simply try three very different values: $0,1.0$, and 2.0 .

Table 3 evaluates equations (9) and (10) for a number of different sets of parameter values. The case denoted "high elasticities" is $\beta=.6, \lambda=.4$; the case denoted "low elasticities" is $\beta=.1, \lambda=0$. The results are unambiguous. If $\varepsilon=0$, revenues keep on rising right up to the point where the tax rate on capital income reaches $100 \%,{ }^{8}$ and the Laffer point for the tax rate on labor

\footnotetext{
'It might be argued that, because of inflationary distortions in the tax system, effective rates of taxation of capital under current inflation rates are over $100 \%$ because taxes are being levied on negative real income. If this is the case, however, the Laffer curve no longer follows from Rolle's Theorem, and may not turn down at all.
} 
income far exceeds what we actually observe. If $\varepsilon=1$, Laffer points do exist for both capital and labor. But the revenue-maximizing tax rates still exceed the rates that characterize the U.S. economy (though perhaps not by much in the case of labor). Only when $\varepsilon$ gets as high as 2 does the peak of the Laffer curve come at tax rates that approximate those actually levied in the U.S. $-26-30 \%$ for labor income and $42-57 \%$ for capital income.

Finally, suppose that the elasticities of supply of capital and labor are really much greater than I have allowed for here. Suppose, for example, that both $\lambda$ and $\beta$ are unity. Equation (9) then implies that $t_{L}^{*}$ will be as low as .30 if $\varepsilon$ exceeds 1.6; equation (10) implies that $t_{K}^{*}$ is 0.4 when $\varepsilon=3.2$.

I conclude that, given the CJL model, the only way the contemporary U.S. economy could find itself on the down side of the Laffer hill is if the parameter $\varepsilon$ is quite sizable. Unfortunately, this is not a parameter we know much about. Pending evidence to the contrary, I am inclined to think it quite small. But nothing much hinges on this belief; all that matters is that $\varepsilon$ not be huge. As Table 3 shows, to be anywhere near the top of the Laffer hill with current tax rates, $\varepsilon$ will have to be about 2 . This means that a $10 \%$ increase in both wage rates and the rate of return on capital must induce a $20 \%$ increase in the quantity of each factor supplied to the market sector. I find this scenario quite fantastic.

\section{SUMMING UP}

To establish the existence of a Laffer curve in theory, we do not need to know anything about either economics or the tax system. Rolle's Theorem will do. But it is a long way from proving the existence of a Laffer curve to arguing that existing taxes are on its downhill side. While the down side of the Laffer hill may perhaps be relevant to very nartowly-based taxes, back-of-the-envelope calculations such as those presented here make it seem highly unlikely that broad-based taxes could fall in this range. The specific model presented in the paper by Canto, Joines, and Laffer does nothing to dispel this belief unless the tax system (at the margin) chases huge amounts of capital and labor out of the market system and into the home production sector (or the underground economy). 
92/ THOUGHTS ON LAFFER CURVE

\section{REFERENCES}

Atkinson, A.B. and N.H. Stern. "Taxation and Incentives in the U.K.: A Comment." Lloyds Bank Review, April 1980.

Canto, V.A., D.H. Joines, and R.I. Webb. "Empirical Evidence of the Effects of Tax Rates on Economic Activity." mimeo, University of Southern California, September 1979. 